九州大学学術情報リポジトリ

Kyushu University Institutional Repository

\title{
Basic Production Analysis of Forages using a Factor of Light Interception Property o Canopy
}

Shimojo, Masataka

Laboratory of Animal Feed Science, Division of Animal Science, Department of Animal and Marine

Bioresource Sciences, Faculty of Agriculture, Kyushu University

Asano, Yoki

Research Fellow, Faculty of Agriculture, Kyushu University

Ikeda, Kentarou

Research Fellow, Faculty of Agriculture, Kyushu University

Ishiwaka, Reiko

Research Fellow, Faculty of Agriculture, Kyushu University

他

https://doi.org/10.5109/4562

出版情報: 九州大学大学院農学研究院紀要. 49 (1)，pp.33-38，2004-02-01. Faculty of Agriculture， Kyushu University

バージョン :

権利関係 : 


\title{
Basic Production Analysis of Forages using a Factor of Light Interception Property of Canopy
}

\section{Masataka SHIMOJO*, Yoki ASANO ${ }^{1}$, Kentarou IKEDA ${ }^{1}$, Reiko ISHIWAKA ${ }^{1}$, Tao SHAO ${ }^{2}$, Hiroyuki SATO ${ }^{3}$, Manabu TOBISA, Yutaka NAKANO ${ }^{4}$, Noriko OHBA ${ }^{5}$, Yasukatsu YANO ${ }^{6}$ and Yasuhisa MASUDA}

\author{
Laboratory of Animal Feed Science, Division of Animal Science, Department of Animal and \\ Marine Bioresource Sciences, Faculty of Agriculture, Kyushu University, \\ Fukuoka 812-8581, Japan \\ (Received October 29, 2003 and accepted November 14, 2003)
}

\begin{abstract}
This numerical study of crop growth rate (CGR) was conducted to investigate the forage productivity per unit of leaf area using mean leaf area weighted with relative light intensity (MLA) in a forage canopy. The results obtained were as follows. (i) The MLA was a kind of combination of light extinction coefficient $(K)$ and leaf area index (LAI) of a canopy. The MLA with large $K$ showed a lower value than that with small $K$ for all LAI and the difference increased with the increase in LAI, suggesting that MLA was small when the shading effect was high due probably to the large area of leaves inclining horizontally. (ii) The application of MLA to CGR led to modified net assimilation rate $(\mathrm{mNAR})$ and modified LAI (mLAI), where CGR $=(\mathrm{mNAR})$. (mLAI). Higher values in mNAR than in NAR suggested that the combination of $K$ and LAI was more important than LAI only in assessing the contribution of canopy leaves to forage productivity, especially when the canopy was large in shading effect and low in the efficiency of light interception.
\end{abstract}

\section{INTRODUCTION}

Shimojo et al. $(1995,1998)$, in numerical studies, applied the mean leaf area weighted with relative light intensity (MLA) and relative amount of light intercepted by MLA (RAL) to the rough estimation of light interception performance of a forage canopy. The MLA includes light extinction coefficient $(K)$ as a component, but does not have the information about light compensation point, respiration and so on. This is the defect in MLA that makes RAL an inaccurate index of estimating the photosynthetic activity. However, relationships between $K$ and RAL (Shimojo et al., 1995, 1998) seems to be in agreement with some studies (Saeki, 1960; Loomis and Williams (1969) as quoted by Gardner et al.,1985; Kubota et al., 1971) which show that the photosynthetic activity with small $K$ is

1 Research Fellow, Faculty of Agriculture, Kyushu University

2 Visiting Research Scientist from Lanzhou Institute of Animal Science and Veterinary Medicine of CAAS, Lanzhou Gansu Province of the People's Republic of China

3 Laboratory of Animal Feed Science, Division of Animal Science, Department of Animal and Marine Bioresource Sciences, Graduate School of Bioresource and Bioenvironmental Sciences, Kyushu University

4 Kyushu University Farm, Fukuoka 811-2307

5 Research Student, School of Agriculture, Kyushu University

${ }^{6}$ Former Technical Specialist

* Corresponding author (E-mail: mshimojo@agr.kyushu-u.ac.jp) 
lower when leaf area index (LAI) is low but is higher in high LAI, when compared with that with large $K$. This is why authors of the present paper have been hesitating to throw the concept of MLA away, and in addition, wish to apply it to the basic production analysis of forages.

The present numerical study was designed to apply MLA to the analysis of crop growth rate (CGR) of forages.

\section{MLA AND ITS APPLICATION TO CGR}

\section{Properties of MLA}

The MLA in a forage canopy results from combining the method by Monsi und Saeki (1953) and the concept suggested by Shimojo et al. $(1995,1998)$. Thus,

$$
\begin{aligned}
\text { MLA } & =\left\{\int_{0}^{A} F \cdot \exp (-K F) d F\right\} /\left\{\int_{0}^{A} \exp (-K F) d F\right\} \\
& =\frac{1}{K} \cdot\left\{1-\frac{K A}{\exp (K A)-1}\right\},
\end{aligned}
$$

where $F=$ cumulative leaf area index from the top layer to the $j$ th layer of canopy leaves, $A=$ an abbreviation of LAI (leaf area index), $K=$ light extinction coefficient.

The values of MLA calculated at two levels of $K$ and five levels of LAI are shown in Table 1 . The value of MLA was always lower than that of LAI, and the difference was large when LAI was high and $K$ was large. This suggests that MLA is associated with the shading effect in canopy caused by the property of leaf distribution, such as leaf area and leaf inclination. The MLA with large $K$ showed a lower value than that with small $K$ for all LAI, and the difference increased with the increase in LAI. In other words, MLA is small when the shading effect is high due probably to the large area of leaves inclining

Table 1. MLA calculated at two levels of $K$ and five levels of LAI

\begin{tabular}{cccc}
\hline & & & $K$ \\
& & 0.4 & 0.8 \\
\hline \multirow{4}{*}{ LAI } & 1 & 0.467 & 0.434 \\
& 2 & 0.868 & 0.744 \\
& 3 & 1.207 & 0.951 \\
& 4 & 1.488 & 1.080 \\
& 5 & 1.717 & 1.157 \\
\hline
\end{tabular}

MLA: mean leaf area of a canopy weighted with relative light intensity,

LAI: leaf area index of the canopy,

$K$ : light extinction coefficient of the canopy.

horizontally.

These results suggest that a forage canopy has its own MLA and the inclusion of $K$ allows MLA to be compared among various light interception properties caused by leaf distribution. In brief, MLA might build a bridge between LAI and $K$ of the canopy. 


\section{An application of MLA to CGR}

The CGR described using net assimilation rate (NAR) and LAI (Watson, 1952; Radford, 1967; Hunt, 1990) is given by

$$
\begin{aligned}
\mathrm{CGR} & =\frac{W_{2}-W_{1}}{t_{2}-t_{1}} \\
& =\left(\frac{\log _{e} A_{2}-\log _{e} A_{1}}{A_{2}-A_{1}} \cdot \frac{W_{2}-W_{1}}{t_{2}-t_{1}}\right) \cdot\left(\frac{A_{2}-A_{1}}{\log _{e} A_{2}-\log _{e} A_{1}}\right),
\end{aligned}
$$

where $W_{t}=$ forage weight at time $t_{i}, A_{t}=\mathrm{LAI}$ at time $t_{i}$, $\left\{\left(\log _{e} A_{2}-\log _{e} A_{1}\right) /\left(A_{2}-A_{1}\right)\right\} \cdot\left\{\left(W_{2}-W_{1}\right) /\left(t_{2}-t_{1}\right)\right\}=$ mean NAR ( $\left.\overline{\mathrm{NAR}}\right)$ over the interval $t_{1}$ to $t_{2},\left(A_{2}-A_{1}\right) /\left(\log _{e} A_{2}-\log _{e} A_{1}\right)=$ mean LAI $(\overline{\mathrm{LAI}})$ over the interval $t_{1}$ to $t_{2}$.

An application of modified NAR using MLA (mNAR) and modified LAI using MLA (mLAI) to CGR is given by

$$
\mathrm{CGR}=\left(\frac{\log _{e} M L A_{2}-\log _{e} M L A_{1}}{M L A_{2}-M L A_{1}} \cdot \frac{W_{2}-W_{1}}{t_{2}-t_{1}}\right) \cdot\left(\frac{M L A_{2}-M L A_{1}}{\log _{e} M L A_{2}-\log _{e} M L A_{1}}\right),
$$

where $\left\{\left(\log _{e} M L A_{2}-\log _{e} M L A_{1}\right) /\left(M L A_{2}-M L A_{1}\right)\right\} \cdot\left\{\left(W_{2}-W_{1}\right) /\left(t_{2}-t_{1}\right)\right\}=$ mean mNAR $(\overline{\mathrm{mNAR}})$ over the interval $t_{1}$ to $t_{2},\left(M L A_{2}-M L A_{1}\right) /\left(\log _{e} M L A_{2}-\log _{e} M L A_{1}\right)=$ mean mLAI (mLAI) over the interval $t_{1}$ to $t_{2}$.

\section{Properties of $\overline{\text { mNAR }}$ and $\overline{\text { mLAI }}$ when applied to CGR}

When $\overline{\text { mNAR }}$ is compared with $\overline{\mathrm{NAR}},\left(W_{2}-W_{1}\right) /\left(t_{2}-t_{1}\right)$ is a common component between them and thus can be eliminated from both terms. Thus, the comparison between $\overline{\text { mNAR }}$ and $\overline{\mathrm{NAR}}$ results in comparing $\left(\log _{e} M L A_{2}-\log _{e} M L A_{1}\right) /\left(M L A_{2}-M L A_{1}\right)$ with $\left(\log _{e} A_{2}-\log _{e} A_{1}\right) /\left(A_{2}-A_{1}\right)$, or rather comparing the reciprocal of $\overline{\text { mLAI }}$ with that of $\overline{\mathrm{LAI}}$. These two are tentatively called $\overline{\text { mNAR }}$ coefficient and $\overline{\text { NAR }}$ coefficient, respectively.

The calculated values for $\overline{\mathrm{mNAR}}$ coefficient and $\overline{\mathrm{NAR}}$ coefficient and those for $\overline{\mathrm{mLAI}}$ and $\overline{\mathrm{LAI}}$ are shown in Table 2 (canopy with constant $K$ ) and Table 3 (canopy with changing $K$ ). In every combination of $K$ and LAI in both Tables 2 and 3, $\overline{\text { mNAR }}$ coefficient was higher than $\overline{\mathrm{NAR}}$ coefficient and thus $\overline{\mathrm{mLAI}}$ was lower than $\overline{\mathrm{LAI}}$. This shows that forage production efficiency per unit of leaf area is emphasized when $\overline{\mathrm{mNAR}}$ is used than when NAR is used. Therefore, the contribution of leaf area to CGR is smaller in the suggested system using $\overline{\mathrm{mNAR}}$ and $\overline{\mathrm{mLAI}}$ compared with the orthodox system using NAR and $\overline{\mathrm{LAI}}$. This implies that the combination of $K$ and LAI is more important than LAI only in assessing the contribution of canopy leaves to forage productivity.

The more detailed comparison of two systems will be given by the use of (mNAR coefficient)/( $\overline{\mathrm{NAR}}$ coefficient) and $(\overline{\mathrm{mLAI}}) /(\overline{\mathrm{LAI}})$ shown in Tables 2 and 3 . The value of (mNAR coefficient)/( $\overrightarrow{\mathrm{NAR}}$ coefficient) was higher when $K$ was larger and/or LAI was higher. Therefore, the corresponding $(\overline{\mathrm{mLAI}}) /(\overline{\mathrm{LAI}})$ showed an inverse relation to (mNAR coefficient)/( $\overline{\mathrm{NAR}}$ coefficient). This suggests that the production efficiency per unit of leaf area is more important than leaf area when the canopy is large in shading effect and low in the efficiency of light interception.

The use of $\overline{\mathrm{mNAR}}$ and $\overline{\mathrm{mLAI}}$ in CGR is to relate the forage productivity to the light interception property of canopy. This system might agree with other studies which show 
Table 2. The values of $\overline{\mathrm{mNAR}}$ coefficient, $\overline{\mathrm{NAR}}$ coefficient, $\overline{\mathrm{mLAI}}$ and $\overline{\mathrm{LAI}}$ in canopy with constant $K$

a) Constant $K(0.4)$ in forage growth shown by the increase in LAI from 2 to 3 and that in LAI from 4 to 5

\begin{tabular}{lcc}
\hline & \multicolumn{2}{c}{ LAI $(K)$} \\
\cline { 2 - 3 } & $2(0.4) \sim 3(0.4)$ & $4(0.4) \sim 5(0.4)$ \\
\hline A: $\overline{\text { mNAR }}$ coefficient & 0.973 & 0.625 \\
B: $\overline{\text { NARcoefficient }}$ & 0.405 & 0.223 \\
A/B & 2.399 & 2.801 \\
& & \\
C: $\overline{\text { mLAI }}$ D: $\overline{\text { LAI }}$ & 1.028 & 1.600 \\
C/D & 2.466 & 4.481 \\
\hline
\end{tabular}

$\overline{\text { mNAR }}$ : mean modified net assimilation rate calculated using MLA

$\overline{\mathrm{NAR}}$ : mean net assimilation rate

mLAI: mean modified leaf area index calculated using MLA

$\overline{\mathrm{LAI}}$ : mean leaf area index

$\overline{\mathrm{mNAR}}$ coefficient $=$ the reciprocal of $\overline{\mathrm{mLAI}}$

$\overline{\mathrm{NAR}}$ coefficient $=$ the reciprocal of $\overline{\mathrm{LAI}}$

b) Constant $K(0.8)$ in forage growth shown by the increase in LAI from 2 to 3 and that in LAI from 4 to 5

\begin{tabular}{lcc}
\hline & \multicolumn{2}{c}{ LAI $(K)$} \\
\cline { 2 - 3 } & $2(0.8) \sim 3(0.8)$ & $4(0.8) \sim 5(0.8)$ \\
\hline A: $\overline{\text { mNAR }}$ coefficient & 1.186 & 0.895 \\
B: $\overline{\text { NAR coefficient }}$ & 0.405 & 0.223 \\
A/B & 2.925 & 4.009 \\
& & \\
C: $\overline{\text { mLAI }}$ & 0.843 & 1.118 \\
D: $\overline{\mathrm{LAI}}$ & 2.466 & 4.481 \\
C/D & 0.342 & 0.249 \\
\hline
\end{tabular}

that the productivity of plants is controlled by the amount of solar radiation intercepted by canopy leaves, provided that the other factors do not limit the growth of plants (Gardner et al., 1985; Charles-Edwards et al., 1986; Simpson and Culvenor, 1987; Sheehy and Johnson, 1988; Humphreys, 1991a, b). However, the present system remains to be examined using actual data. 
Table 3. The values of $\overline{\mathrm{mNAR}}$ coefficient, $\overline{\mathrm{NAR}}$ coefficient, $\overline{\mathrm{mLAI}}$ and $\overline{\mathrm{LAI}}$ in canopy with changing $K$

a) Changing $K$ from 0.4 to 0.5 in forage growth shown by the increase in LAI from 2 to 3 and that in LAI from 4 to 5

\begin{tabular}{lcc}
\hline & \multicolumn{2}{c}{ LAI $(K)$} \\
\cline { 2 - 3 } & $2(0.4) \sim 3(0.5)$ & $4(0.4) \sim 5(0.5)$ \\
\hline A: $\overline{\text { mNAR }}$ coefficient & 1.003 & 0.658 \\
B: $\overline{\text { NARcoefficient }}$ & 0.405 & 0.223 \\
A/B & 2.473 & 2.948 \\
& & \\
C: $\overline{\text { mLAI }}$ & 0.997 & 1.520 \\
D: $\overline{\text { LAI }}$ & 2.466 & 4.481 \\
C/D & 0.404 & 0.339 \\
\hline
\end{tabular}

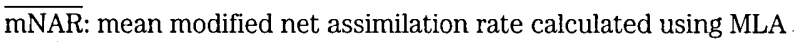

$\overline{\mathrm{NAR}}$ : mean net assimilation rate

$\overline{\mathrm{mLAI}}$ : mean modified leaf area index calculated using MLA

$\overrightarrow{\mathrm{LAI}}$ : mean leaf area index

$\overline{\mathrm{mNAR}}$ coefficient $=$ the reciprocal of $\overline{\mathrm{mLAI}}$

$\overline{\mathrm{NAR}}$ coefficient $=$ the reciprocal of $\overline{\mathrm{LAI}}$

b) Changing $K$ from 0.8 to 0.9 in forage growth shown by the increase in LAI from 2 to 3 and that in LAI from 4 to 5

\begin{tabular}{lcc}
\hline & \multicolumn{2}{c}{ LAI $(K)$} \\
\cline { 2 - 3 } & $2(0.8) \sim 3(0.9)$ & $4(0.8) \sim 5(0.9)$ \\
\hline A: $\overline{\text { mNAR }}$ coefficient & 1.224 & 0.937 \\
B: $\overline{\text { NAR coefficient }}$ & 0.405 & 0.223 \\
A/B & 3.018 & 4.198 \\
& & \\
C: $\overline{\text { mLAI }}$ & 0.817 & 1.067 \\
D: $\overline{\mathrm{LAI}}$ & 2.466 & 4.481 \\
C/D & 0.331 & 0.238 \\
\hline
\end{tabular}

\section{CONCLUSIONS}

It was suggested that the use of MLA in CGR gave some information about the light interception property of canopy to the basic production analysis of forages.

\section{REFERENCES}

Chars-Edwards, D. A., D. Doley and G. M. Rimmington 1986 The light-use Efficiency. In "Modelling Plant Growth and Development", Academic Press Australia, North Ryde, pp. 56-70

Gardner, F. P., R. B. Pearce and R. L. Mitchell 1985 Carbon fixation by crop canopies. In "Physiology of Crop Plants", The Iowa State University Press, Iowa, pp. 31-57

Humphreys, L. R. 1991a Effects of defoliation on the growth of tropical pastures. In "Tropical Pasture Utilisation", Cambridge University Press, Cambridge, pp. 46-65 
Humphreys, L. R. 1991b The modification of botanical composition by grazing: plant replacement and interference. In "Tropical Pasture Utilisation", Cambridge University Press, Cambridge, pp. 66-87

Hunt, R. 1990 Basic Growth Analysis. Unwin Hyman Ltd., London.

Kubota, F., W. Agata and E. Kamata 1971 Dry matter production of forage plants. IV. Influence of light extinction coefficient $(K)$ on dry matter production in forage plant populations-theoretical analysis-. J. Japan. Grassl. Sci., 17: 243-249 (in Japanese with English summary)

Monsi, M. und T. Saeki 1953 Über den Lichtfaktor in den Pflanzengesellschaften und seine Bedeutung für die Stoffproduktion. Jap. J. Bot., 14: 22-52

Radford, P. J. 1967 Growth analysis formulae-their use and abuse. Crop Sci., 7: 171-175

Saeki, T. 1960 Interrelationships between leaf amount, light distribution and total photosynthesis in a plant community. Bot. Mag. Tokyo, 73: 55-63

Sheehy, J. E. and I. R. Johnson 1988 Physiological models of grass growth. In "The Grass Crop: the Physiological Basis of Production", ed. by M. B. Jones and A. Lazenby, Chapman and Hall Ltd., London, pp. 243-275

Shimojo, M., Y. Masuda, Y. Imura, M. Tobisa, Y. Nakano and I. Goto 1995 Estimation of light intercepting performance of plant canopy using mean leaf area weighted with relative light intensity. J. Fac. Agr., Kyushu Univ., 39: 235-242

Shimojo, M., T. Bungo, Y. Imura, M. Tobisa, N. Koga, S. Tao, M. Yunus, Y. Nakano, I. Goto, M. Furuse and Y. Masuda 1998 Mean leaf area of the canopy for light interception by forages and mean retention time of feed in the rumen for feed ingestion by ruminants as investigated using simple models. $J$. Fac. Agr., Kyushu Univ., 43: 111-118

Simpson, R. J. and R. A. Culvenor 1987 Photosynthesis, carbon partitioning and herbage yield. In "Temperate Pastures: their Production, Use and Management", ed. by J .L. Wheeler, C. J. Pearson and G.E.Robards, Australian Wool Corp./CSIRO, Collingwood, pp. 103-118

Watson, D. J. 1952 The physiological basis of variation in yield. Adv. Agron., 4: 101-145 